Thorax (1963), 18, 238

\title{
Systemic arterial patterns in the lung and clubbing of the fingers
}

\author{
MARGARET T UR NER-W A R W I CK
}

From the Institute of Diseases of the Chest, London, S.W.3

The close association between clubbing of the fingers and some forms of heart and lung disease have been reviewed fully by Mendlowitz (1942). The frequent association of clubbing of the extremities with cyanotic heart disease led to the suggestion that hypoxia was an important causal factor (Mendlowitz, 1942), but hypoxia alone does not account for the presence of finger clubbing in many types of lung disease. Cudkowicz and Wraith (1957a) could find no single clinical common factor in 27 patients with finger clubbing and various pulmonary disorders.

From the anatomical standpoint, Cudkowicz and Armstrong (1953) suggested that the essential feature in the lungs of patients with clubbing was the presence of precapillary communications between the bronchial and pulmonary arteries. Later they supported this suggestion with right heart catheterization studies in 28 patients with finger clubbing and various lung disorders ; they found high oxygen saturations in the pulmonary artery branch to the diseased lobe and concluded that there must be a left to right shunt at pulmonary artery level. More recently Cudkowicz, Calabresi, Nims, and Gray (1959) have shown in four patients with clubbing that the output of the left ventricle exceeded that of the right, and they regarded this as further evidence in favour of a bronchopulmonary shunt in the lung. But there is an alternative explanation for the greater output of the left ventricle which does not invoke a precapillary bronchopulmonary shunt.

In the present work the finer detail of the systemic vessels to the lung has been studied using a microradiographic technique which has been specially developed to demonstrate bronchial vessels. It will be shown that although systemicpulmonary anastomoses are commonly found in the lungs from patients with finger clubbing, expansion of the systemic vascular bed within the lungs is a more constant feature. Although it has been widely recognized that the bronchial arteries enlarge in many lung diseases, it has been insufficiently appreciated that there is a wide varia- tion in the patterns of this vascular increase, an any of these are characteristic of the underlying disease (Turner-Warwick, 1961). Preliminary evidence is also presented which suggests that the peripheral vascular changes, identified in the fingerg as clubbing, may be part of a widespread vasculat change affecting many tissues.

\section{MATERIAL AND METHODS}

Bronchial artery measurements were made on 80 lungs from 44 patients. The major diseases studied wers primary bronchial carcinoma (21 lungs from 2 震 patients), emphysema (31 lungs from 19 patients diffuse pulmonary fibrosis (12 lungs from 6 patients and bronchiectasis (16 lungs from 10 patients). Of th 44 patients studied, the fingers were moderately of grossly clubbed in 24 and were normal in 20.

CLUBBing The fingers of all patients were examine before death. Clubbing was recognized when, fror the lateral view, the angle between the nail-fold and the nail-bed was obliterated. Clubbing was graded a@ moderate when the angle was $180^{\circ}$ and gross whe the angle was greater than $180^{\circ}$, i.e., convex. Using this definition, only irrefutable nail-bed changes were. accepted as clubbing, and all doubtful cases were regarded as normal. In nine patients the radial artery was injected after death with $80 \%$ 'Micropaque' in $15 \%$ gelatin, and radiographs were taken of the fingers. The vascular pattern of the clubbed and the unclubbed fingers was easily distinguished and con firmed the clinical assessment during life (Fig. 1).

LUNGS The systemic vessels to the lungs werf injected via the aorta after death using a technique described previously (Turner-Warwick, 1961). The् injection mass used in this study was an $80 \%$ suspenk sion of barium sulphate as 'Micropaque' (Demancey\& in $15 \%$ gelatin. Injection was made at a pressure of $120 \mathrm{~mm}$. Hg and continued for 30 minutes. The lungs were gently inflated with air to their normal size ando cooled. After radiographs had been taken the lung? were filled with $10 \%$ formalin through the bronch and fixed for 10 days; thereafter sagittal slices of individual lung lobes were cut $0.5 \mathrm{~cm}$. thick, and radiographs of these were taken on fine grained 'Line 
FIG. 1. Radiographs of the lateral view of (left) clubbed finger and (right) normal finger after injection of the radial artery. $\times 2$.

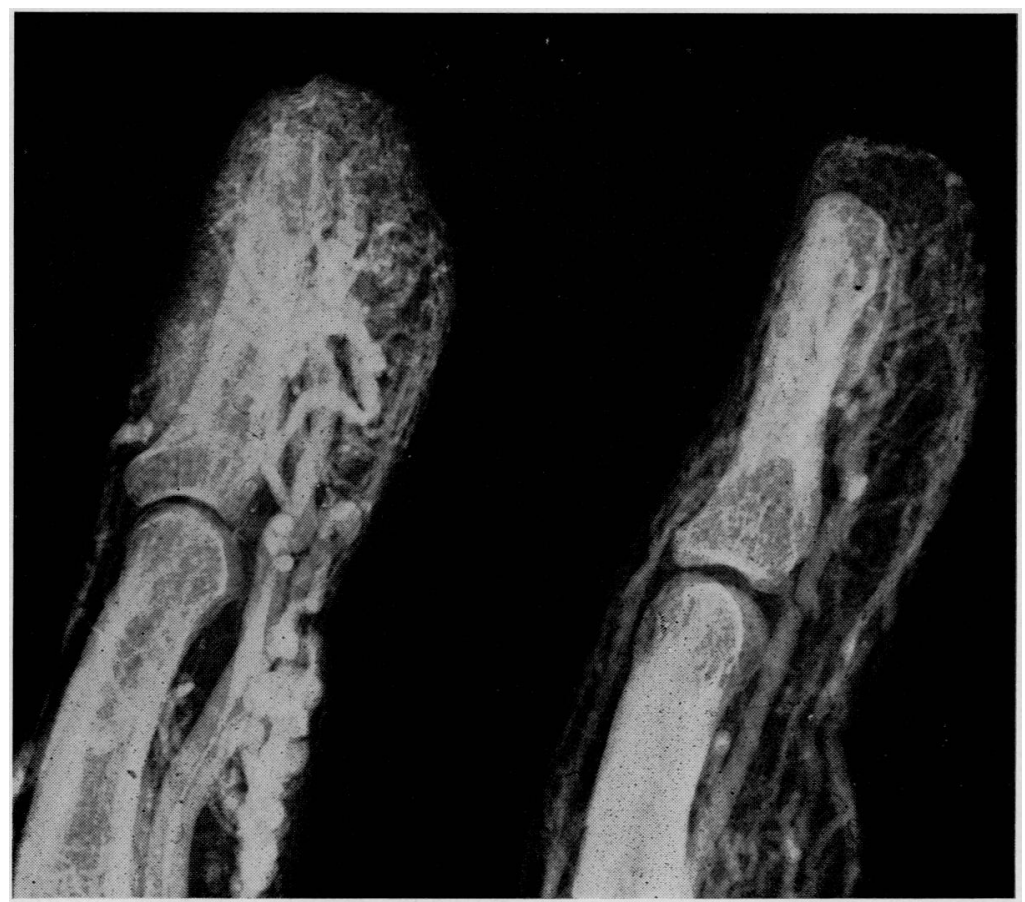

film (Ilford) which could be magnified without loss of definition.

Under these conditions the systemic arteriolar branches of $30 \mu$ and over were regularly filled, but overflow into the capillaries did not occur. In normal lungs no filling of the pulmonary arterial bed occurred after injection of the bronchial arteries, but in diseased lungs filling of the pulmonary arteries was not infrequently seen and indicated the presence of precapillary bronchopulmonary communications, the detail of which was identified on the magnified radiographs of lung slices.

The lungs were studied histologically to relate the distribution of disease to the abnormal vascular patterns observed radiologically. The presence of bronchitis was assessed by measuring the wall/gland ratio of the major bronchi, using the method described by Lynne Reid (1960). This ratio is normally less than 0.3 but was increased in all pat:ents in this study who clinically had bronchitis.

BRONCHIAL ARTERY MEASUREMENTS The diameter of all major bronchial arteries over $0.5 \mathrm{~mm}$. to each lung was measured at origin, and the cross-sectional area of each of these main vessels was calculated. The total cross-sectional area of bronchial arteries to each lung was determined by addition and is arbitrarily referred to in this paper as the 'bronchial artery size'. Many vessels of less than $0.5 \mathrm{~mm}$. were seen supplying the lung through the pulmonary ligament, especially when the vascular supply to the lungs was increased in disease, but these vessels were not measured.
Therefore any increase above normal in the calculated bronchial artery size to a lung tended to underestimate the actual increase in the systemic supply to it.

Measurements were made on 80 lungs. In 11, more than one major disease was found within the same lung; the bronchial artery sizes of these lungs have been indicated in the analysis of each disease which may have contributed to the resulting abnormal vascular pattern.

\section{RESULTS}

Figure 2 shows the relation between finger clubbing and the bronchial artery size of each lung from patients with bronchial carcinoma, emphysema and chronic bronchitis, diffuse pulmonary fibrosis, and bronchiectasis.

In 15 normal lungs obtained from patients dying from causes other than lung disease the bronchial artery size was found to range from $0.9 \mathrm{~mm} .^{2}$ to $3.5 \mathrm{~mm} .^{2}$ with a mean of $2.15 \mathrm{~mm}^{2}$ (indicated in Fig. 2 by cross hatching).

Of the 44 patients studied, 24 had moderate or gross clubbing, and in 21 of these the bronchial artery size was greater than normal in one or both lungs. Conversely, of the 20 patients with normal fingers the bronchial artery size was enlarged in only two. Thus in 39 out of 44 patients with lung disease, those with finger clubbing had large bronchial arteries whereas those without clubbing 


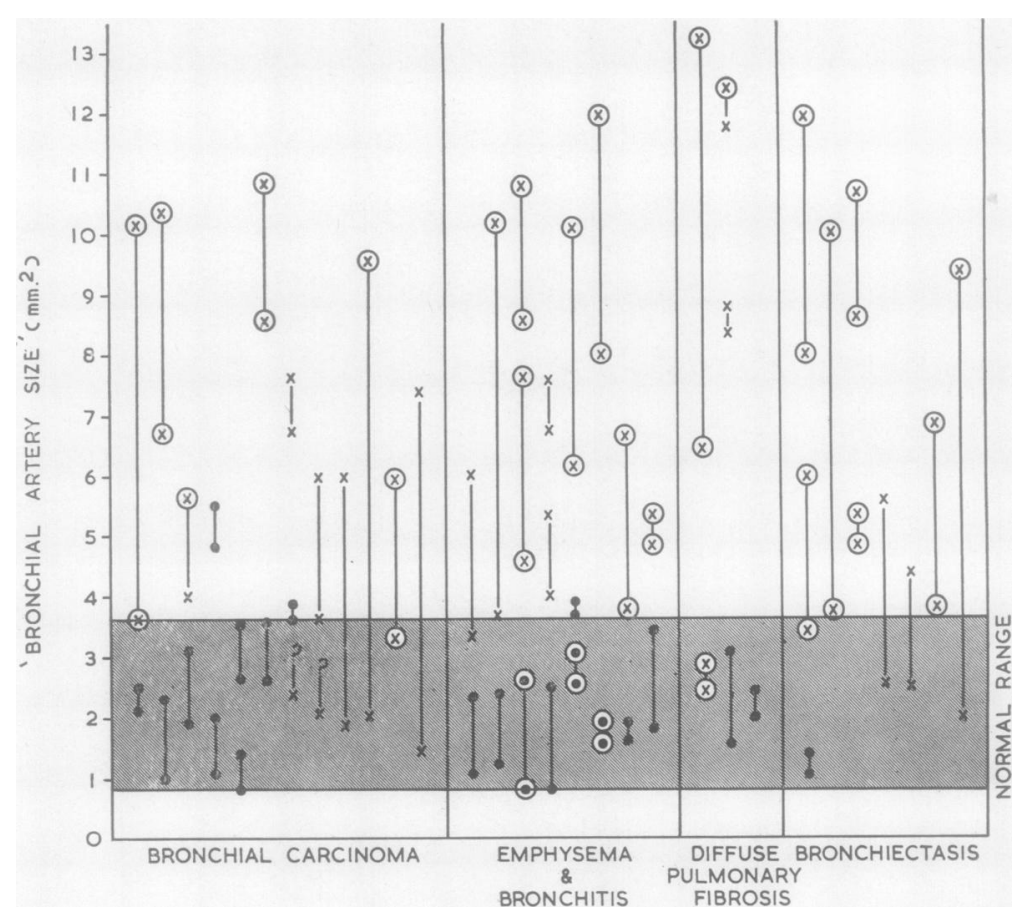

FIG. 2. Relation between finger clubbing and the bronchial artery size of each lung. $x$ 'Bronchial artery size' of lungs from patients with finger clubbing. $\bullet$ 'Bronchial artery size' of lungs from patients with normal fingers. $O$ Numerous systemicpulmonary anastomoses present. I Joins the 'bronchial artery sizes' of the two lungs from each patient. A patient will appear in more than one column if more than one disease is present.

had bronchial arteries of normal size. This relation was demonstrated irrespective of the nature of the underlying disease. The five exceptional cases will be discussed later in the analyses of the peripheral bronchial artery patterns in individual diseases.

Two possible causes for this bronchial artery enlargement have been investigated: (1) the presence of precapillary bronchopulmonary anastomoses; and (2) the increase in the extent of distribution of the systemic vascular bed within the lung.

BRONCHOPULMONARY ANASTOMOSES The bronchial artery sizes have been ringed (Fig. 2) in those lungs where numerous anastomoses were found. Precapillary bronchopulmonary anastomoses were seen frequently in association with bronchial artery enlargement, but there were numerous exceptions. In 11 lungs the bronchial artery size was greater than normal but no anastomoses were demonstrated : conversely, anastomoses were readily seen in 10 lungs with normal-sized bron- chial arteries. Bronchial artery enlargement does not therefore depend solely on the presence of $\underset{0}{x}$ anastomoses, although their frequent association 3 suggests that anastomoses are often a concomitant feature.

Altogether there were eight patients with finger clubbing in whom no anastomoses were present $?$ in either lung, and three patients with normal $\frac{}{8}$ fingers in whom numerous anastomoses were $=$ found. This suggests that finger clubbing does not $N$ depend on the presence of systemic-pulmonary 0 anastomoses alone.

INCREASE OF THE SYSTEMIC VASCULAR BED IN THE LUNGS These results suggest that enlargement of the main bronchial arteries is constantly associated $\Phi_{\infty}$ with an increase in their peripheral distribution in the lung. This finding will be illustrated by describing some of the characteristic bronchial artery patterns seen in different lung diseases and? correlating these with the presence of finger clubbing. 


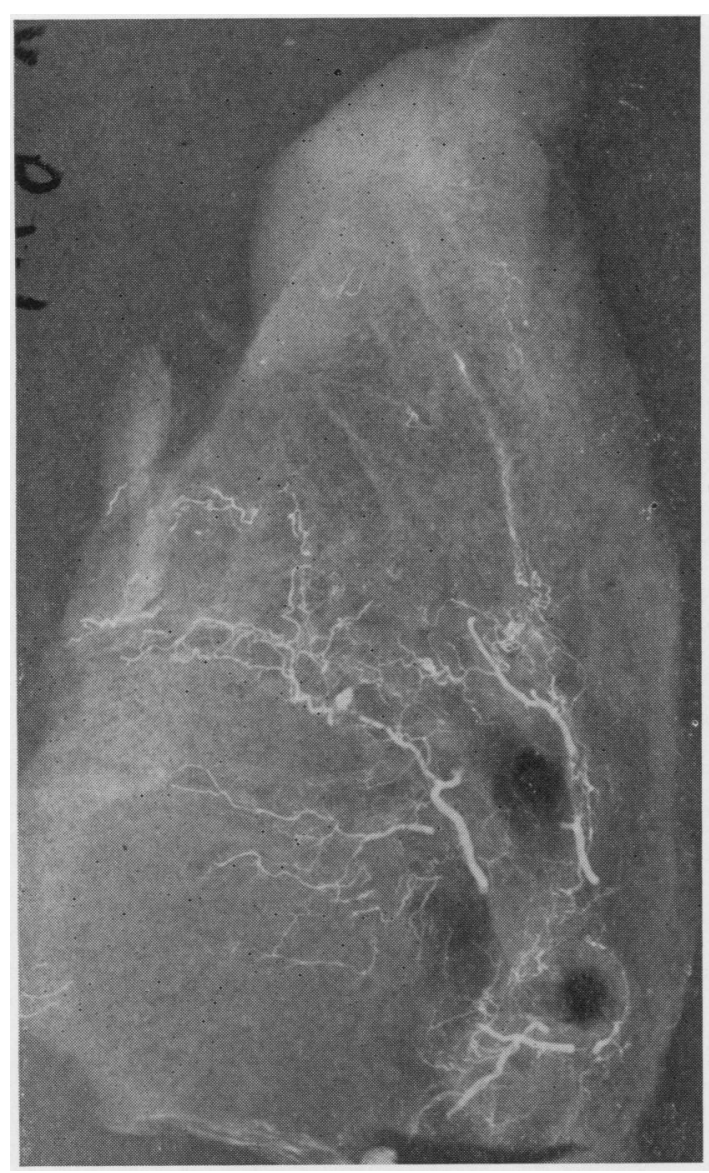

FIG. 3. Radiograph of the normal bronchial artery pattern in a sagittal slice of lung. Systemic artery injection. $\times 1 \cdot 25$.

Normal lung In the normal lung the bronchial artery branches radiate from the hilum, closely following the axial bronchi, leaving the intervening areas and the respiratory tissue in the lung periphery unsupplied by systemic vessels of macroscopic size (i.e., $30 \mu$ ) (Fig. 3). Only a limited area on the mediastinal visceral pleura immediately surrounding the hilum is supplied by systemic arteries; the costal and diaphragmatic visceral pleurae are normally supplied from the pulmonary artery.

Carcinoma Table I shows the distribution of the systemic vessels in 21 cases of primary bronchial carcinoma. This table shows that in bronchial carcinoma there is a close correlation between bronchial artery enlargement and finger clubbing. This increase of bronchial artery size is commonly related to an increased vascular supply to the primary tumour and also to a more generalized increase in the systemic arterial pattern, particularly of the systemic vessels of the pleura.

In nine lungs from nine patients the bronchial artery sizes were normal (Group I, Table I) ; the vascular supply to the primary tumour was small and the bronchial arteries to the opposite lung were normal in size; seven of these nine patients had normal fingers. Finger clubbing was seen in two patients, but in both of these the bronchial artery injection to the carcinomatous lung was incomplete owing to terminal atelectasis due to obstruction by tumour.

In 12 lungs the main bronchial artery size to the carcinomatous lung was greater than normal (Group II, Table I) ; this enlargement was usually found in relation to an extensive vascular supply to the primary growth (Fig. 4) and to other lobes of the same lung (Table I). Six lungs in this group were of particular interest because the bronchial arteries to the lung on the side opposite to the carcinoma were also increased: this enlargement was related to a generalized increase in the systemic vascular bed, particularly the pleural systemic vessels (Fig. 5). Although emphysema was found in five of these lungs, it will be shown later that emphysema alone rarely causes such an increase in the bronchial artery pattern. No other disease was found in these lungs to account for the increased systemic vascular supply, and a possible explanation for this finding is suggested later.

Of the 12 patients with enlarged bronchial arteries (Group II, Table I) 10 had obvious clubbing. In one (H.C) of the two exceptional cases, the bronchial artery measurements were only slightly greater than normal $\left(3.60 \mathrm{~mm}^{2}\right.$ and 3.85 $\mathrm{mm} .{ }^{2}$, the vascular supply to the tumour and other regions of both lungs was not increased, and the bronchial artery pattern in this case was similar to that of the lungs from other patients in group I with normal fingers. In the other (L.F. in Table I), the enlarged bronchial arteries were related entirely to large infiltrated lymph nodes; the peripheral distribution of the bronchial arteries within the lungs and to the primary tumour was not increased and was similar to that in the other patients with normal fingers in group $\mathbf{I}$.

Emphysema and chronic bronchitis In 17 lungs from nine patients with emphysema and bronchitis, the bronchial artery sizes were normal, and in these there was no increase in the systemic vascular pattern in the periphery. The fingers of eight of the nine patients in this group were normal. Although the bronchial artery sizes in this group 


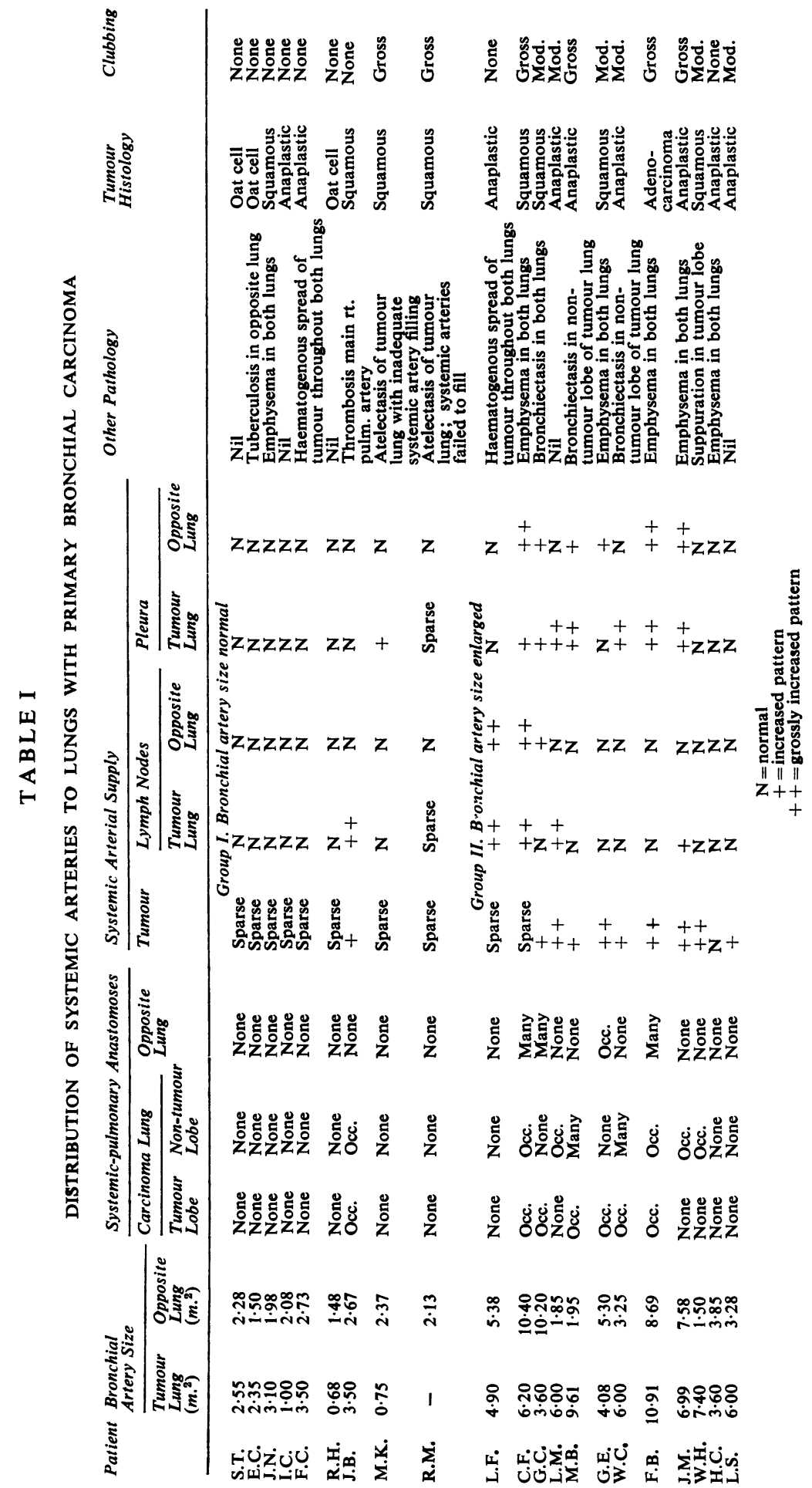




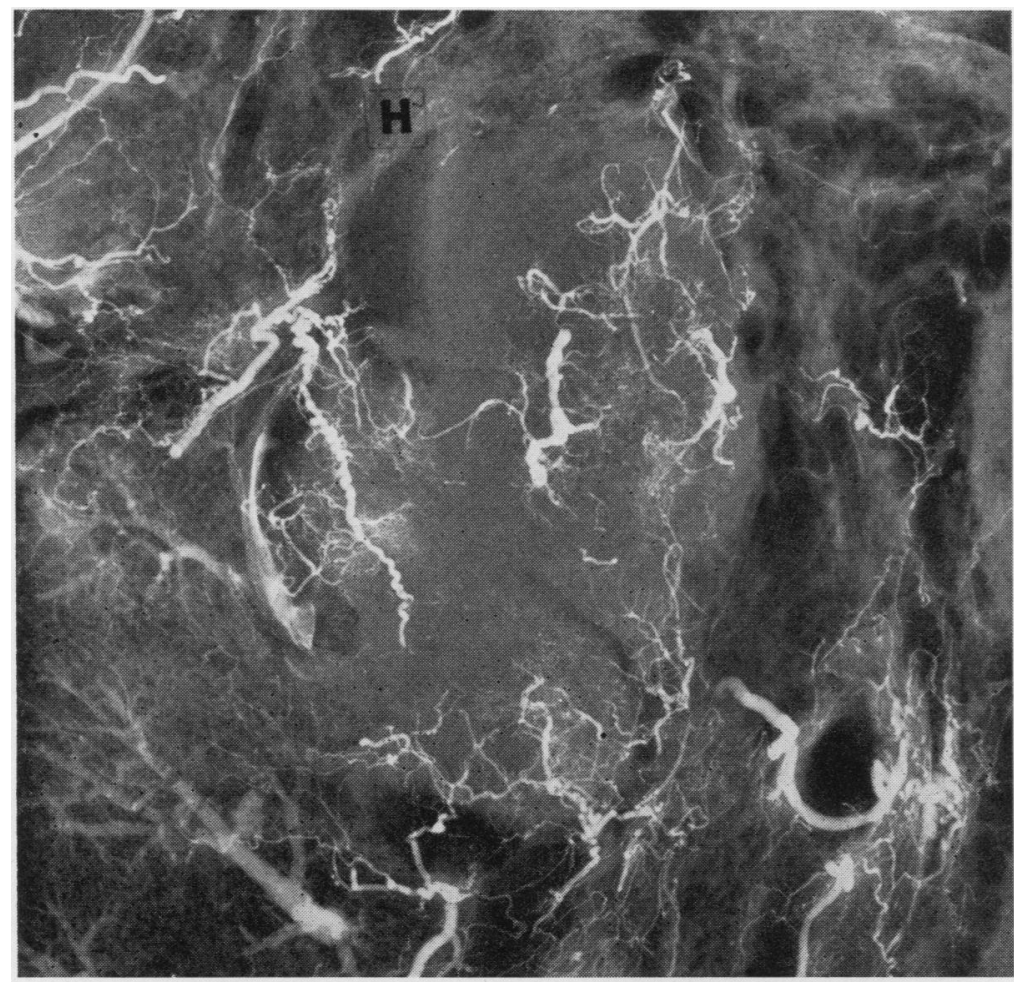

FIG. 4. Radiograph showing the bronchial artery supply to a primary bronchial carcinoma. $\times 2$.

FIG. 5. Radiograph showing the increased arterial supply to the pleura in a lung on the opposite side to a primary bronchial carcinoma. Systemic artery injection. $\times 1 \cdot 25$.

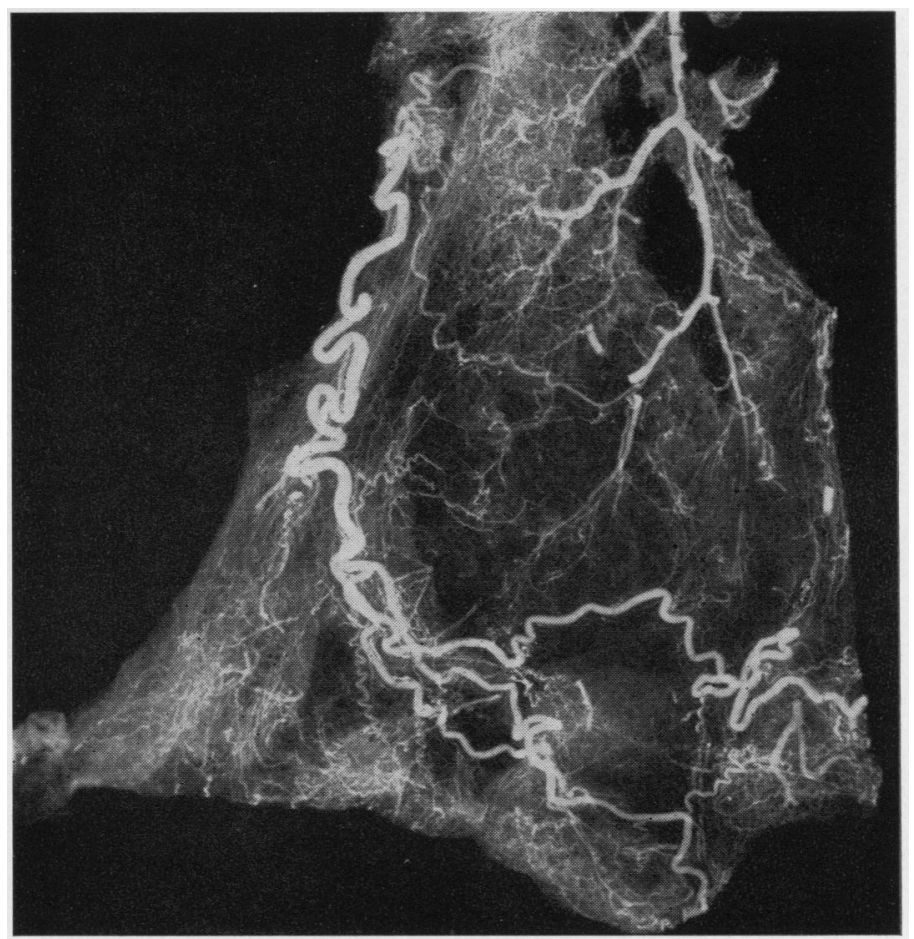




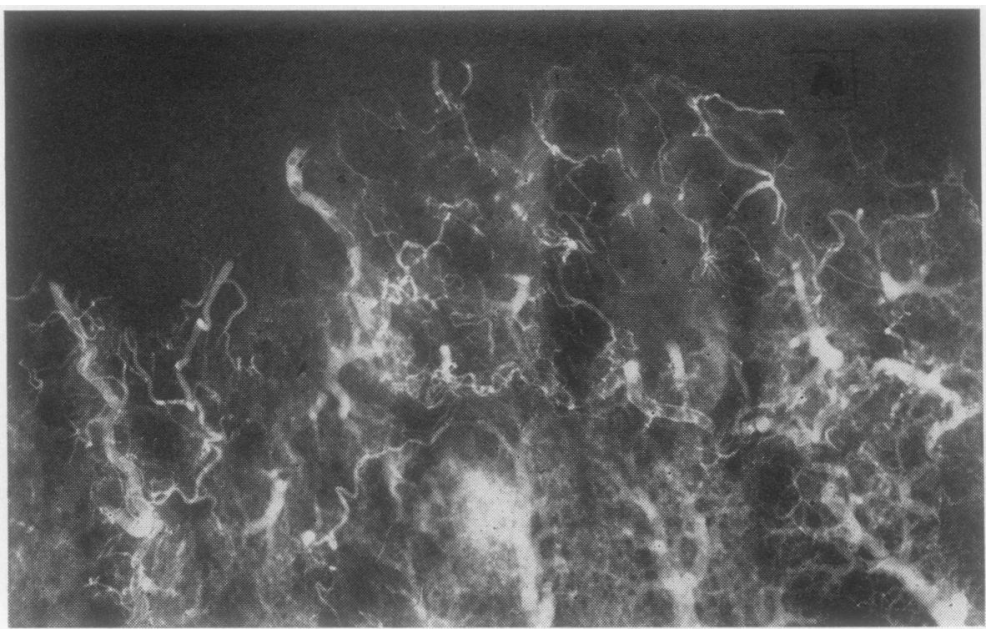

FIG. 6. Radiograph showing the $\stackrel{\overrightarrow{0}}{\overrightarrow{0}}$ systemic artery network around $\overrightarrow{\vec{\omega}}$ subpleural emphysematous bullae. $\times 2$. (The pulmonary artery $\underset{2}{ }$ pattern seen in the lower part of the. illustrction is due to a separate $\vec{\infty}$ elective injection in this particulario case.)

T A B LE I I

SYSTEMIC ARTERIAL SUPPLY TO LUNGS WITH EMPHYSEMA CORRELATED WITH SOME CLINICAL FACTORS

\begin{tabular}{|c|c|c|c|c|c|c|c|c|c|c|}
\hline \multirow[t]{2}{*}{ Patient } & \multirow{2}{*}{$\begin{array}{l}\text { Bronchial } \\
\text { Artery } \\
\text { Size } \\
\left(\mathrm{mm} \cdot{ }^{2}\right)\end{array}$} & \multirow{2}{*}{$\begin{array}{l}\text { Systemic- } \\
\text { pulmonary } \\
\text { Anastomoses }\end{array}$} & \multirow{2}{*}{$\begin{array}{l}\text { Age } \\
(y r .)\end{array}$} & \multirow{2}{*}{$\begin{array}{l}\text { Duration } \\
\text { of } \\
\text { Symptoms } \\
(y r .)\end{array}$} & \multicolumn{2}{|l|}{ Bronchitis } & \multicolumn{2}{|c|}{ Pulmonary Hypertension } & \multirow{2}{*}{$\begin{array}{l}\text { Systemic } \\
\text { Blood } \\
\text { Pressure } \\
(\mathrm{mm} . \mathrm{Hg})\end{array}$} & \multirow{2}{*}{ 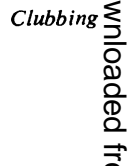 } \\
\hline & & & & & $\begin{array}{l}\text { Clinical } \\
\text { (Yellow } \\
\text { Sputum) }\end{array}$ & $\begin{array}{l}\text { Wall/Gland } \\
\text { Ratio* } \\
\text { (of Main } \\
\text { Bronchi) }\end{array}$ & $\overline{\text { Clinical }}$ & $\begin{array}{l}\text { Wall Lumen } \\
\text { Ratio (of } \\
\text { Muscular } \\
\text { Pulmonary } \\
\text { Arteries, \%) } \dagger\end{array}$ & & \\
\hline \multicolumn{11}{|c|}{ Group I. Bronchial artery size normal } \\
\hline F.D. & $\begin{array}{l}2 \cdot 36 \\
1 \cdot 00\end{array}$ & $\begin{array}{l}\text { Many } \\
\text { Many }\end{array}$ & 55 & 12 & Present & 0.7 & Present & 28 & 11575 & None \\
\hline A.D. & $\begin{array}{l}2.49 \\
1.05\end{array}$ & $\begin{array}{l}\text { Many } \\
\text { None } \\
\text { None }\end{array}$ & 51 & 20 & Absent & $0 \cdot 3$ & Absent & 11 & 12080 & None \\
\hline I.W. & $\begin{array}{l}1.05 \\
2.69 \\
0.93\end{array}$ & $\begin{array}{l}\text { None } \\
\text { None }\end{array}$ & 68 & 20 & Present & 0.6 & Absent & 12 & 11670 & None \\
\hline H.C. & $\begin{array}{l}2.55 \\
0.93\end{array}$ & $\begin{array}{l}\text { None } \\
\text { None }\end{array}$ & 60 & 40 & Present & 0.6 & Absent & 11 & 16090 & None \\
\hline J.T. & $\begin{array}{l}2 \cdot 56 \\
3 \cdot 05\end{array}$ & $\begin{array}{l}\text { Occ. } \\
\text { Occ. }\end{array}$ & 49 & 28 & Present & 0.7 & Present & 40 & 12080 & None \\
\hline C.P. & $\begin{array}{l}1.95 \\
1.75\end{array}$ & $\begin{array}{l}\text { None } \\
\text { None }\end{array}$ & 63 & 15 & Present & 0.6 & Present & 50 & 16095 & None \\
\hline V.D. & $\begin{array}{l}1.98 \\
1.85\end{array}$ & $\begin{array}{l}\text { Many } \\
\text { Many }\end{array}$ & 40 & 18 & Absent & 0.4 & Present & 11 & 11560 & None \\
\hline A.L. & $\begin{array}{l}3 \cdot 45 \\
1 \cdot 80\end{array}$ & $\begin{array}{l}\text { Occ. } \\
\text { None }\end{array}$ & 74 & 6 & Absent & 0.6 & Present & 38 & 7040 & None \\
\hline W.C. & $\begin{array}{l}3.25 \\
6.00\end{array}$ & $\begin{array}{l}\text { None } \\
\text { (Carcinoma i }\end{array}$ & $\begin{array}{l}58 \\
\text { in this lung) }\end{array}$ & 0 & Absent & 0.4 & Absent & 7 & 11060 & Modera \\
\hline \multicolumn{11}{|c|}{ Group II. Bronchial artery size enlarged } \\
\hline G.E. & $\begin{array}{l}5 \cdot 30 \\
4 \cdot 08\end{array}$ & $\begin{array}{l}\text { Occ. } \\
\text { (Carcinoma i }\end{array}$ & $\begin{array}{l}64 \\
\text { in this lung) }\end{array}$ & 34 & Present & 0.6 & Absent & 16 & 14080 & Moderate \\
\hline H.C. & $\begin{array}{l}3 \cdot 85 \\
3 \cdot 60\end{array}$ & $\begin{array}{l}\text { None } \\
\text { (Carcinoma i }\end{array}$ & $\begin{array}{l}71 \\
\text { in this lung) }\end{array}$ & 0 & Absent & - & Absent & 9 & 12080 & None \\
\hline G.C. & $\begin{array}{r}10 \cdot 20 \\
3 \cdot 60\end{array}$ & $\begin{array}{l}\text { Many } \\
\text { (Carcinoma i }\end{array}$ & $\begin{array}{l}67 \\
\text { in this lung) }\end{array}$ & 7 & Present & 0.5 & Absent & 22 & 12095 & Moderate्ట \\
\hline F.B. & $\begin{array}{r}8 \cdot 69 \\
10 \cdot 91\end{array}$ & Many & $\begin{array}{l}60 \\
\text { in this lung) }\end{array}$ & 10 & Absent & 0.4 & Absent & 12 & 10070 & Gross \\
\hline J.M. & $\begin{array}{l}7.58 \\
6.99\end{array}$ & $\begin{array}{l}\text { Occ. } \\
\text { (Carcinoma i }\end{array}$ & $\begin{array}{l}64 \\
\text { in this lung) }\end{array}$ & 0 & Absent & 0.4 & Absen & 7 & 120,70 & Gross \\
\hline C.F. & $\begin{array}{r}10 \cdot 38 \\
6 \cdot 20\end{array}$ & $\begin{array}{l}\text { Many } \\
\text { (Carcinoma }\end{array}$ & $\begin{array}{l}62 \\
\text { in this lung) }\end{array}$ & 0 & Absent & 0.4 & Absent & 12 & $110 / 60$ & Gross \\
\hline C.R. & $\begin{array}{r}8.00 \\
12.00\end{array}$ & $\begin{array}{l}\text { Many } \\
\text { Many }\end{array}$ & 54 & 10 & Present & 0.9 & Present & 9 & 11575 & Gross \\
\hline A.U. & $\begin{array}{r}6 \cdot 70 \\
3 \cdot 75\end{array}$ & $\begin{array}{l}\text { Many } \\
\text { Many }\end{array}$ & 41 & 39 & Present & 0.7 & Present & 22 & $110 / 80$ & Gross \\
\hline R.B. & $\begin{array}{l}5.30 \\
4.90\end{array}$ & $\begin{array}{l}\text { Many } \\
\text { Many }\end{array}$ & 42 & 38 & Present & 0.7 & Present & 17 & $130 / 80$ & Moderate \\
\hline D.B. & $\begin{array}{l}4 \cdot 70 \\
7 \cdot 85\end{array}$ & $\begin{array}{l}\text { None } \\
\text { Occ. }\end{array}$ & 50 & 10 & Absent & 0.3 & Present & 12 & $125 / 85$ & Moderat@ \\
\hline
\end{tabular}

*Normally less 0.3 ; increased in bronchitis, L. Reid (1960). †Normally less $15 \%$; increased in pulmonary hy pertension, Heath-Edwards (1958). 
T A B LE III

DISTRIBUTION OF SYSTEMIC ARTERIAL PATTERN IN LUNGS WITH WIDESPREAD FIBROSIS CORRELATED

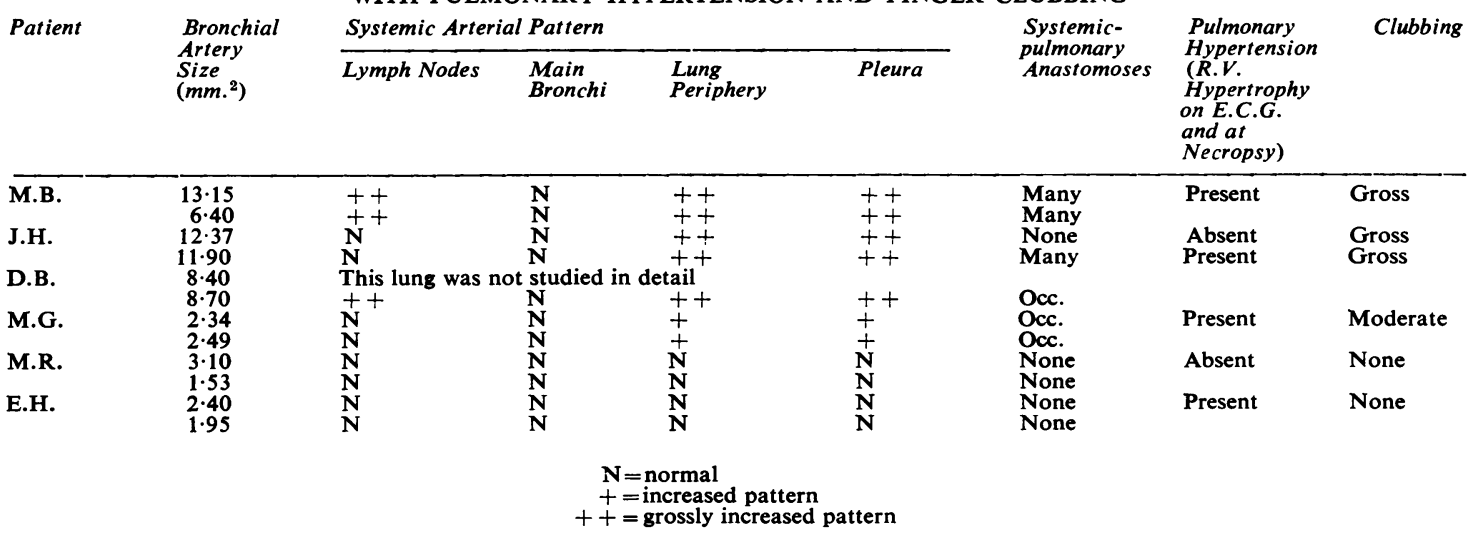

were within normal limits, minor abnormalities (but no increase) of distribution were demonstrated: full discussion of these is outside the scope of the present paper and has been reported elsewhere (TurnerWarwick, 1961).

The main bronchial arteries were enlarged in 14 lungs from 10 patients with emphysema. In four of these the increase was associated with changes attributable to extensive bronchiectasis, but in eight destructive emphysema was the only disease found. However, five of these eight lungs were from patients with a bronchial carcinoma in the opposite lung, and the finger clubbing and bronchial artery enlargement may have been related to the latter and not to the presence of emphysema. In only two lungs was the expanded bronchial arterial pattern related to uncomplicated emphysema, and in these the pleural branches were particularly increased both in size and in extent of distribution, forming networks about subpleural bullae (Fig. 6).

In Table II the lungs have been grouped according to bronchial artery size. In group I are lungs with bronchial artery sizes lying within the normal range; in group II are lungs with bronchial artery sizes greater than normal. Comparison of groups I and II in Table II shows that the bronchial artery enlargement is closely related to the presence of finger clubbing, but not clearly to the presence of broncho-

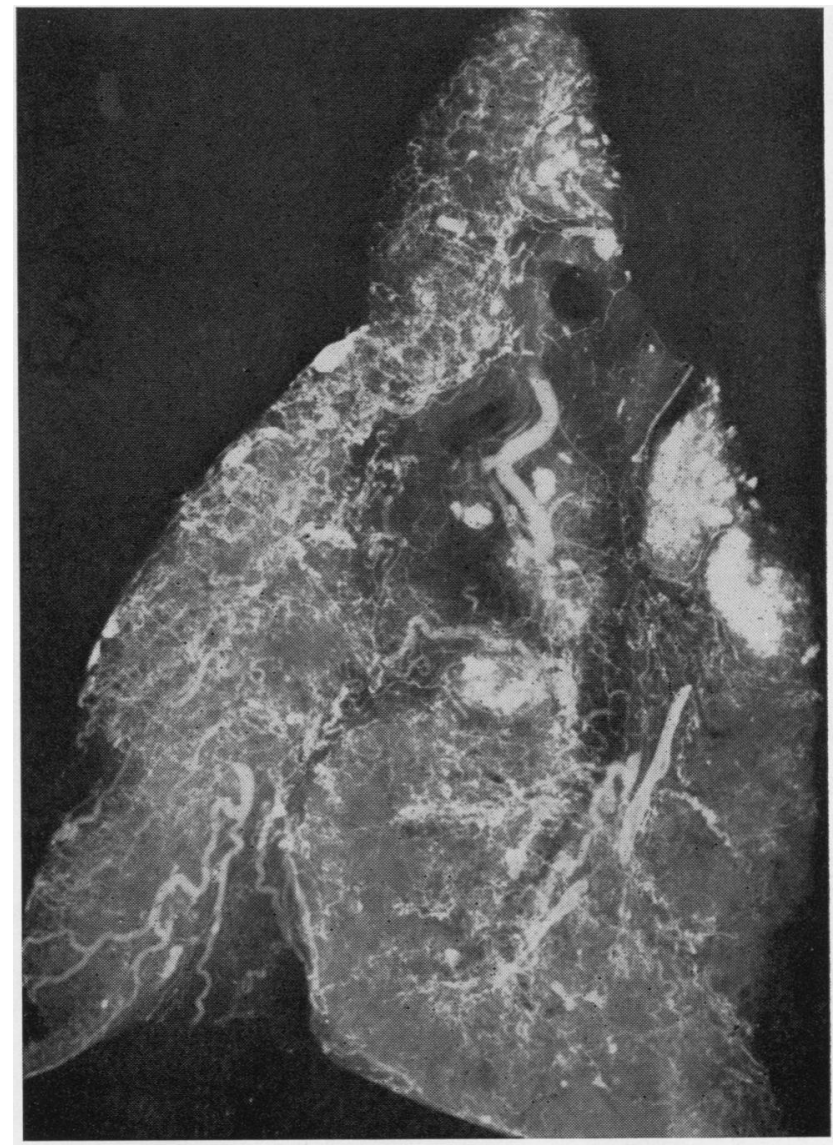

FIG. 7. Radiograph of the bronchial artery pattern in diffuse interstitial pulmonary fibrosis. Systemic artery injection. $\times 1 \cdot 25$. 
pulmonary anastomoses, age of the patient, duration of the disease, associated bronchitis, or evidence of pulmonary or systemic hypertension.

Pulmonary fibrosis (see Table III) In diffuse pulmonary fibrosis a massive expansion of the systemic vascular bed was frequently found (Fig. 7, cf. normal Fig. 2). In the periphery of the lung, numerous bronchial artery branches ran outwards from the axial bronchi to form dense networks in the intervening areas of lung. Numerous anastomoses were seen in five lungs, but in three (all from patients with gross clubbing) only very occasional anastomoses were found, although the bronchial artery sizes were grossly enlarged (8.4 mm. ${ }^{2}, 8.7 \mathrm{~mm}^{2}$, and $11.8 \mathrm{~mm}^{2}$ ) and the vascular bed greatly expanded (Table III). There were two patients in whom a generalized increase did not occur; in both of these the fingers and the bronchial artery sizes were normal. In one patient with moderate finger clubbing, the bronchial artery sizes were not enlarged (M.G., Table III) but a study of the peripheral vascular pattern showed a moderately increased pattern, similar to those already described: the absence of main bronchial artery enlargement remains unexplained.

Bronchiectasis Bronchiectasis was found in 16

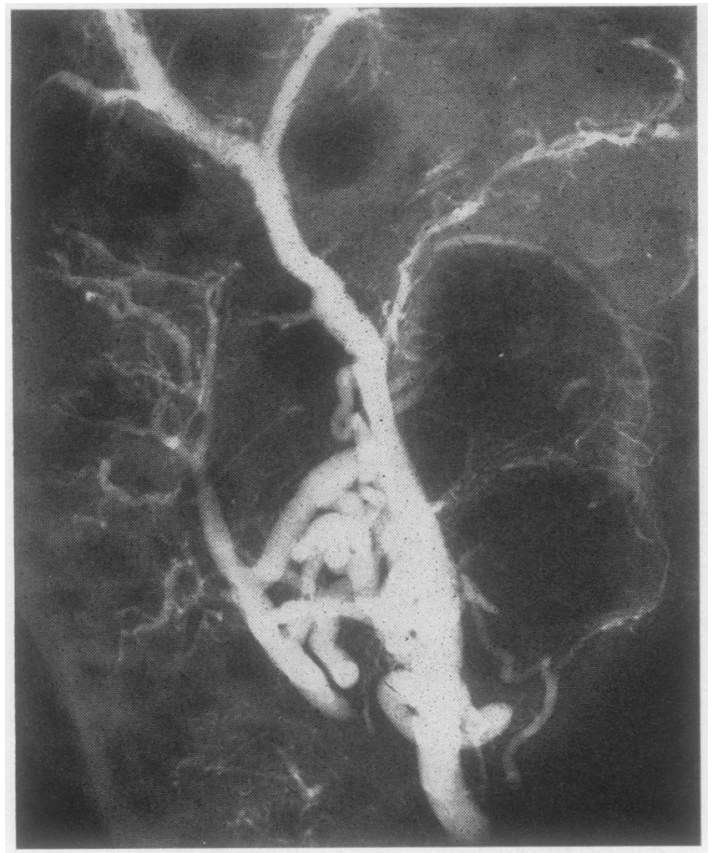

FIG. 8. Radiograph of the bronchial artery pattern in bronchiectasis, showing large and tortuous systemic arteries around the axial pulmonary artery, and branches forming networks around bronchiectatic sacs. $\times 4$. lungs, and in 12 the bronchial arteries were enlarged. Large anastomoses were found in nine, but these $\frac{\bar{c}}{\sigma}$ were not the only bronchial artery abnormality $\mathbb{D}$ seen: the systemic vascular bed was considerably

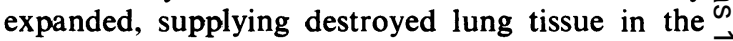
neighbourhood of bronchiectatic cysts (Fig. 8). $\vec{\circ}$ Finger clubbing was present in all the patients with $\overrightarrow{\vec{A}}$ enlarged bronchial arteries and in two in whom ${ }_{\sigma}^{\omega}$ no anastomoses were demonstrated. In one patient $\overrightarrow{\vec{F}}$ with normal-sized bronchial arteries, the fingers were also normal.

\section{DISCUSSION}

The results presented here suggest that in patients with lung disease, finger clubbing is closely related $\vec{c}$ to enlargement of the systemic vascular supply to $\frac{\mathbb{O}}{8}$ the lungs. This enlargement may sometimes be due $\underset{\mathbb{D}}{\mathbb{D}}$ partly to an increase of precapillary shunts between $\frac{1}{3}$ the systemic and pulmonary circulations, but these $\stackrel{\mathbb{}}{-}$ shunts are not invariably present, and it appears $\vec{\theta}$ that an increase in the systemic vascular bed is of greater importance. The explanation of the frequent finding of anastomoses in the neighbourhood of systemic vascular proliferation is suggested in their morphology (Liebow, Hales, and Lindskog, 1949). In areas of vascular proliferation large numbers of fine systemic arterioles can be found, $\stackrel{\varnothing}{\varnothing}$ some of which connect end to end with minute $\overrightarrow{\overrightarrow{0}}$ pulmonary arterioles (Fig. 9); this form of 3 anastomosis is quite distinct from larger 'isolated' anastomoses found in pulmonary hypertension and congenital heart disease (Turner-Warwick, 1961) (Fig. 10). It is suggested that in lungs in which there is a great expansion in the distribution of $\frac{\tilde{x}}{x}$ the systemic vessels, occasional proliferating branches will incidentally establish communication. with pulmonary arterioles.

The extent of bronchial artery expansion varies greatly in individual patients with the same lung 의 disease. Factors determining this variation have $>$ been considered. There is no evidence that the age of the patient or the duration of the disease is related to the vascular response. Short (1958) found o that the systemic pattern of the intestine was 0 restricted in systemic hypertension, but in the present study the mean systemic blood pressure was no higher in patients with normal bronchiak artery patterns than in those showing vascular $\frac{\odot}{\mathscr{C}}$ proliferation.

The evidence suggesting that a large part of 0 the expanded systemic vascular patterns seen in the lung represents new vessel formation has been $\mathbb{Q}$ discussed by Liebow, Hales, and Bloomer (1959)这 and confirmed by combined radiological and histo- -0 logical studies (Turner-Warwick, 1961). Experi- 


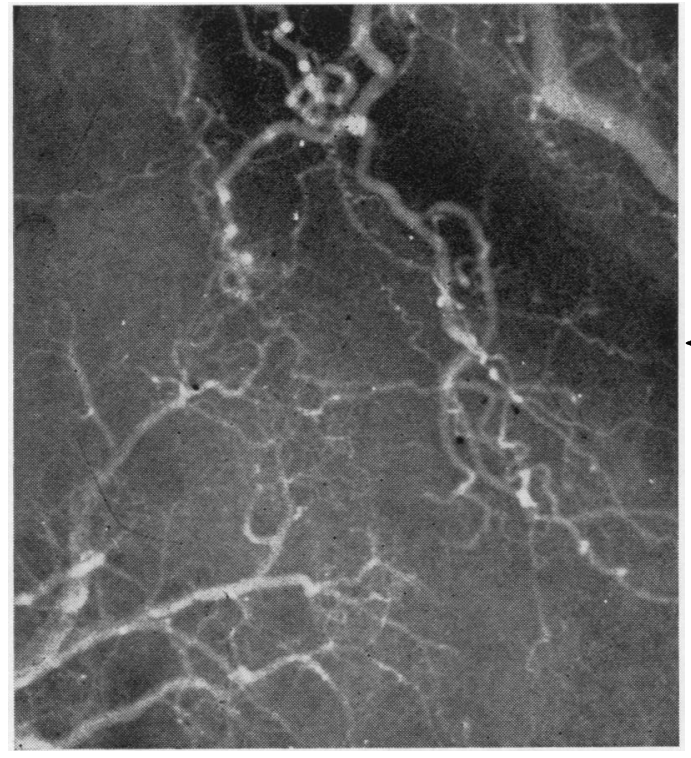

$\uparrow$

Pulmonary artery branches

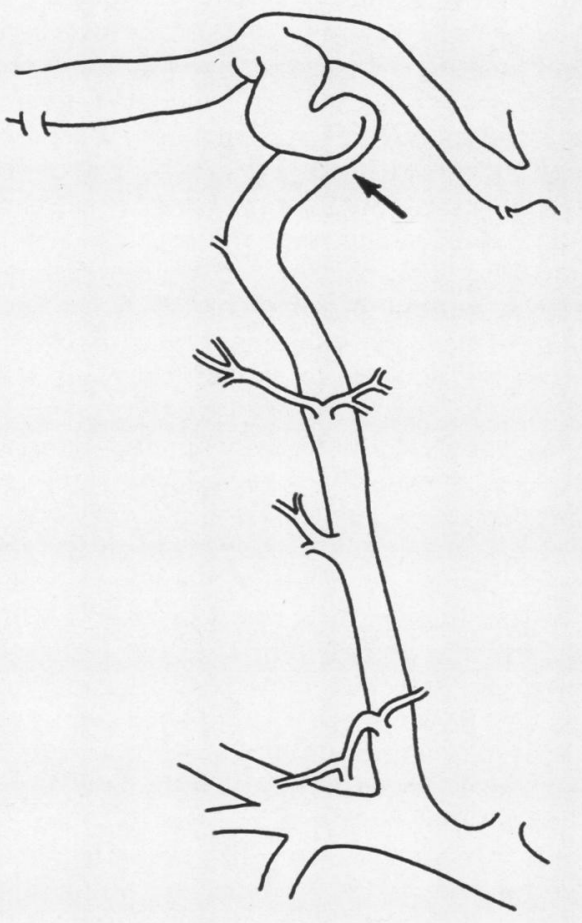

Bronchial artery branches

FIG. 9. Radiograph showing bronchial artery proliferation with incidental filling of pulmonary arterioles in the vicinity, in a lung from a case of scleroderma. $\times 9$.

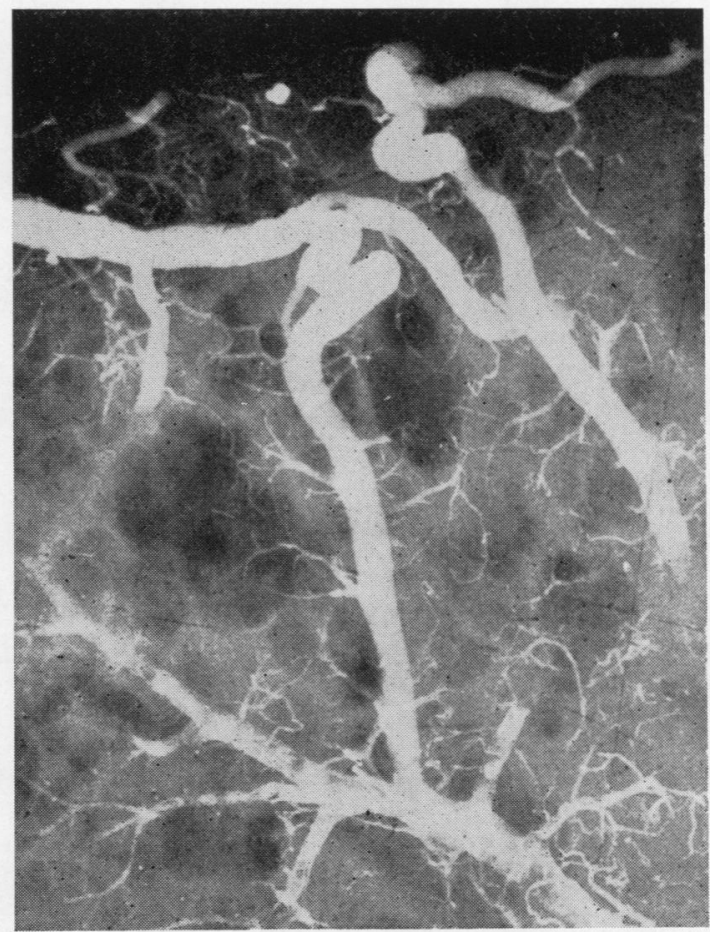

FIG. 10. Radiograph showing an 'isolated' end-to-end anastomosis between a pleliral systemic artery and a branch of the pulmonary artery in a lung from a patient with pulmonary hypertension and interstitial pulmonary fibrosis. 
mental studies by Liebow et al. (1959) have demonstrated the development of these vessels from solid cords of cells in the neighbourhood of a ligated pulmonary artery. Little is known of the stimuli causing growth of new vessels in diseased tissue, but it seems probable that it is these that play a fundamental role in determining the extent of systemic vascular proliferation in lung disease.

The essential change in finger clubbing appears to be an increased vascularity of the terminal phalanges (Lovell, 1950 ; Mendlowitz, 1942 and 1954). Numerous theories have been propounded on the mechanisms by which lung disease determines these nail-bed changes. Mendlowitz (1942) suggested that arterial desaturation and increased finger blood flow were important: however, in many cases of lung disease arterial desaturation is not present, and Ginsburg (1958), using an accurate plethysmographic technique, reported that the hand blood flow is not increased in uncomplicated finger clubbing. Various reflex nervous pathways have been suggested. Flavell (1956) reported partial resolution of clubbing and improvement in the symptoms of osteoarthropathy after vagotomy, and Hansen confirmed this finding (1952). However, the influence of these procedures on uncomplicated clubbing cannot be assessed as detailed blood flow studies have not been reported. Cudkowicz and Armstrong (1953) postulated that afferent stimuli from ischaemic lung tissue dilated bronchopulmonary anastomoses and 'spilled' to the corresponding level of sympathetic distribution in the arms, dilating arteriovenous anastomoses in the fingers. This theory fails to account for the clubbing in the toes often observed in lung disease. Endocrine malfunction may play some part in patients with clubbing and osteoarthropathy (Fried, 1943 ; Freeman, 1958), and high oestrogen levels have been found in patients with clubbing, osteoarthropathy, and bronchial carcinoma (Ginsburg, 1958). The aetiological factors causing clubbing with osteoarthropathy are not necessarily identical with those causing simple clubbing (Ginsburg, 1958 ; Semple and McCluskie, 1955) and there is no evidence to suggest the importance of endocrine factors in uncomplicated clubbing.

Ferritin is a 'tissue metabolite' which in its reduced form inhibits the vasoconstrictive action of circulating adrenaline, and is normally broken down in the lungs. Hall (1959) considered (on very indirect evidence) that it by-passed the ventilatory tissue in various lung diseases to appear unchanged in the systemic circulation. He postulated the presence of direct anatomical pulmonary artery to pulmonary vein shunts in the lung (Tobin and
Zariquiey, 1950), but the existence of such shunts is still unproven, and in extensive studies by many workers, using both radiographic and cast techniques, these shunts have not been found (Weibel, 1959 ; Short, 1958).

If a 'tissue metabolite' were produced by a nonventilating mass of new tissue within the lung itself, then the anatomical pathway described in the present work would account for its transit directly into the systemic circulation without involving pulmonary artery venous shunting. It has been shown here that in patients with finger clubbing the systemic arteriolar bed within the lungs, supplying non-ventilating inflammatory or tumour tissue, is greatly increased. This vascular bed may have no precapillary communication with the pulmonary system, and its venous drainage will follow the intrapulmonary bronchial veins which join the pulmonary veins (Liebow, 1953). Under these circumstances venous blood from tissue within the lung supplied by systemic arteries will drain (in the absence of precapillary systemicpulmonary anastomoses) to the intrapulmonary bronchial veins, and so via the pulmonary veins to the left atrium ; it will not traverse the capillary bed of the pulmonary vessels.

If a greatly expanded systemic arterial bed within the lungs is associated with an increased systemic arterial blood flow through the lungs, then the haemodynamic effect of such an increased flow through the systemic arteries $\rightarrow$ intrapulmonary bronchial veins $\rightarrow$ pulmonary veins would impose an additional load on the left ventricle and could account for the finding of an increased left ventricular output (Cudkowicz et al., 1959). The presence of systemic-pulmonary anastomoses is not therefore prerequisite to explain their results.

It has been shown earlier that the extent of the vascular supply to new tissue in the lung varies greatly, and the results reported here suggest that in lung diseases, finger clubbing develops only when the blood supply to the non-ventilating tissue within the lung is copious, a blood supply in fact usually supplied by the bronchial arteries.

The vascular supply and venous return from sequestrated lung segments are relevant to this discussion. Patients with uninfected sequestrated lung segments do not usually have finger clubbing, and yet large areas of tissue within the lung are supplied by aberrant systemic vessels. These facts do not invalidate the theory just presented, because the venous drainage of a sequestrated lung segment is entirely different from the pathway outlined above, since it follows the azygos vein to the right atrium (Smith, 1956 ; Turner-Warwick, 1961), and will thereafter traverse the pulmonary capillary 
bed. Blood from a sequestrated segment therefore does not by-pass the capillary bed of the lung, and so finger clubbing would not be expected.

In extrapulmonary disease the anatomical pathways by-passing the lungs are probably different. In cardiac disease clubbing is especially associated with cyanosis (Mendlowitz, 1942), and the right to left intracardiac shunt would allow 'vasodilator substance' to short-circuit the lungs. In cirrhosis of the liver there is evidence that two pathways may develop whereby venous blood by-passes the lungs. Calabresi and Abelmann (1957) have shown in cast preparations that a venous plexus behind the lower end of the oesophagus connects the portal and pulmonary veins. However, attempts to demonstrate a physiological shunt with Krypton have yielded negative results (Shaldon, Caesar, Chiandussi, Williams, Sheville, and Sherlock, 1961).
Other evidence suggests that in cirrhosis, unlike lung disease, direct pulmonary arteriolar to venule shunts may develop (Rydell and Hoffbauer, 1956).

There is general agreement that, although finger clubbing is similar in appearance in diseases of the liver, heart, and lungs, the incidence of pulmonary osteoarthropathy is strikingly different. The explanation of this might depend on the different types of tissue responsible for 'tissue metabolite' production, for in cardiac and liver disease a major proportion of the shunted blood is mixed venous blood from normal tissues while, according to the present hypothesis, in lung disease the entire volume of blood by-passing the lungs would be from abnormal inflammatory or tumour tissue. Osteoarthropathy is also found in idiopathic clubbing (Camp and Scanlan, 1948): detailed reports on the pulmonary vascular bed are not

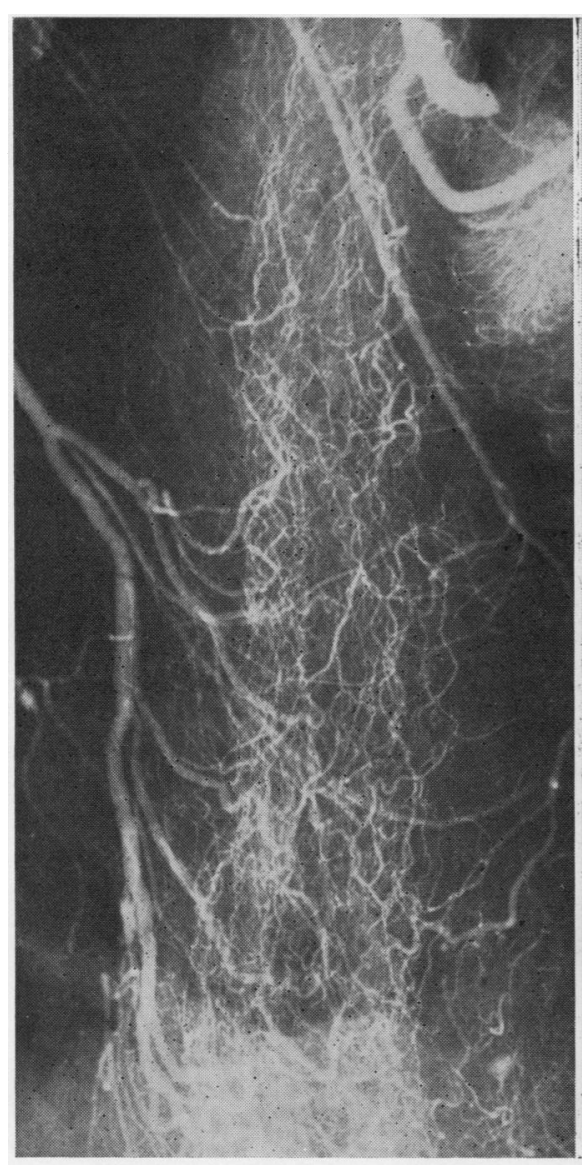

(a)

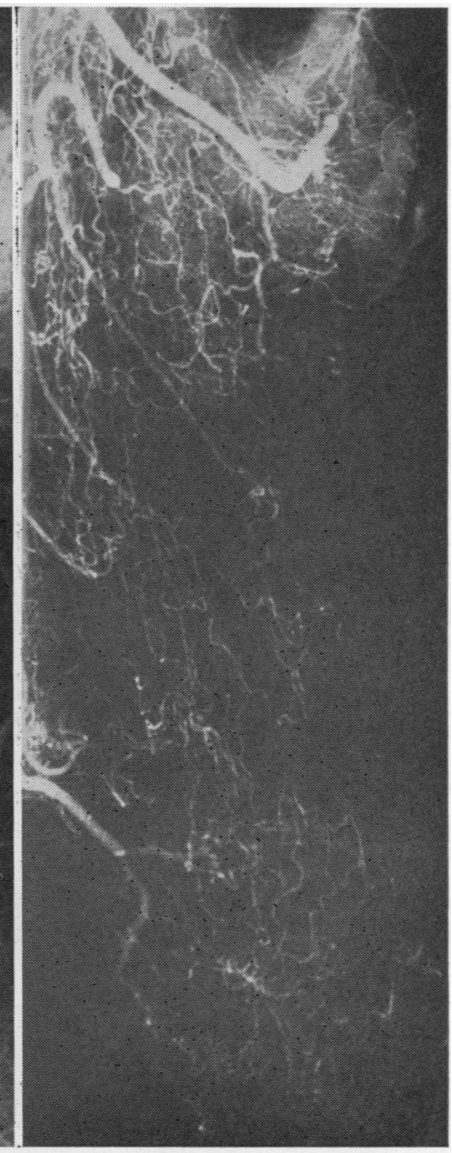

(b)

FIG. 11. The systemic arterial pattern of the oesophagus: (a) finger clubbing present; (b) finger clubbing absent. $\times 1 \cdot 25$. 
available but it is of interest that an increased bronchial artery flow has been measured both by Fishman, Turino, Brandfonbrener, and Himmelstein (1958) and by Cudkowicz, Abelmann, Levinson, Katznelson, and Jreissaty (1960), and this suggests that an increased systemic vascular pattern to the lung may well be found.

The anatomy of the systemic supply to the lungs in subacute bacterial endocarditis has not been reported but it is hoped that information on this will be obtained.

If 'vasodilator' material is responsible for changes in the circulation in the fingers, evidence might be found of abnormal vascular patterns in other parts of the systemic circulation. Preliminary work has been done on the oesophageal arteriolar pattern in patients with lung disease, and from this it appears that the vascularity is increased in patients with finger clubbing (Fig. 11). This finding requires further detailed study. If the vasodilator stimulus affects parts of the systemic circulation other than the nail-bed, the finding of a bilateral increase in bronchial artery patterns in unilateral disease, mentioned earlier in relation to bronchial carcinoma, might be explained.

The present study is limited to an anatomical demonstration of the vascular pathways present in the lungs of patients with finger clubbing. It is likely that the mechanism of clubbing will be elucidated finally by physiological and biochemical methods.

\section{SUMMARY}

A microradiographic technique has been used to study the bronchial arteries in acquired lung disease.

When finger clubbing is present in patients with lung disease, the bronchial arteries are larger than normal, irrespective of the nature of the disease.

The enlargement is not due entirely to the development of systemic-pulmonary anastomoses but is related to a great expansion of the systemic vascular bed in the lungs in the neighbourhood of inflammatory or tumour tissue.

The anatomy of the systemic arterial pathways in the lung is discussed in relation to the theory that finger clubbing is caused by a 'vasodilator' substance.
Preliminary evidence suggests that the peripheral vascular changes identified in the fingers as $\frac{\bar{c}}{\bar{c}}$ clubbing may be part of a more widespread change $\frac{\vec{\sigma}}{\sigma}$ affecting many tissues.

\section{REFERENCES}

Calabresi, P., and Abelmann, W. H. (1957). Porto-caval and porto- $\overrightarrow{0}$ pulmonary anastomoses in Laennec's cirrhosis and in heart failure. J. clin. Invest., 36, 1257. Camp, J. D., and Scanlan, R. L. (1948). Chronic idiopathic hyper

Cudkowicz, L., Abelmann, W. H., Levinson, G. E., Katznelson, G. , $\underset{\overrightarrow{2}}{\rightleftharpoons}$ and Jreissaty, R. M. (1960). Bronchial arterial blood flow. Clin. $\times$ Sci., 19, 1 .

and Armstrong, J. B. (1953). Finger clubbing and changes in the bronchial circulation. Brit. J. Tuberc., 47, 227.

- Calabresi, M., Nims, R. G., and Gray, F. D. (1959). The simultaneous estimation of right and left ventricular outputs $\omega$ applied to a study of the bronchial circulation in patients with $\infty$

chronic lung disease. Amer. Heart J., 58, 743. nificance of clubbing in common lung disorders. Brit.J. Tuberc., 51, 14 .

(1957b). A method of study of the pulmonary circulation $(\mathcal{D}$ in finger clubbing. Thorax, 12, 313.

Fishman, A. P., Turino, G. M., Brandfonbrener, M., and Himmel-음 stein, A. (1958). The 'effective' pulmonary collateral blood flow in man. J. clin. Invest., 37, 1071.

Flavell, G. (1956). Reversal of pulmonary hypertrophic osteoarthropathy by vagotomy. Lancet, 1, 260.

Freeman, A. G. (1958). Gross digital clubbing and exophthalmic ophthalmoplegia in thyroid disorders. Ibid., $2,57$.

Fried, B. M. (1943). Chronic pulmonary osteoarthropathy. Dyspituitarism as a probable cause. Arch. intern. Med., 72, 565.

Ginsburg, J. (1958). Observations on the peripheral circulation in hypertrophic pulmonary osteoarthropathy. Quart. J. Med., 27,

Hall, G. H. (1959). The cause of digital clubbing. Testing a new hypothesis. Lancet, 1, 750 .

Hansen, J. L. (1952). Acta med. scand., 142, suppl. 266, p. 467.
Liebow, A. A. (1953). The broncho-pulmonary venous collateral circulation with special reference to emphysema. Amer. J. Path., 29, 251 .

_ Hales, M. R., and Bloomer, W. E. (1959). In Pulmonary Circulation: An International Symposium, 1958, ed. W. R. Adams and $\overline{\bar{O}}$ I. Veith. Chapter beginning on p. 79: Relation of bronchial to I. Veith. Chapter beginning on $\mathrm{p}$. 79: Relation of bronch
pulmonary vascular tree. Grune and Stratton, New York.

_- - and Lindskog, G. E. (1949). Enlargement of the bronchial arteries, and their anastomoses with the pulmonary arteries in bronchiectasis. Amer. J. Path., 25, 211.

Lovell, R. R. H. (1950). Observations on the structure of clubbed fingers. Clin. Sci., 9, 299.

Mendlowitz, M. (1942). Clubbing and hypertrophic osteo-arthropathy. Medicine (Baltimore), 21, 269.

- (1954). The Digital Circulation. Grune and Stratton, New York. $\times$

Reid, L. (1960). Measurement of the bronchial mucous gland laver: $O$ A diagnostic yardstick in chronic bronchitis. Thorax, 15, 132.

Rydell, R., and Hoff bauer, F. W. (1956). Multiple pulmonary arterio-. venous fistulas in juvenile cirrhosis. Amer. J. Med., 21, 450.

Semple, T., and McCluskie, R. A. (1955). Generalized hypertrophic osteoarthropathy, in association with bronchial carcinoma. $B \cdot i t$.? med. J., 1, 754.

Shaldon, S., Caesar, J., Chiandussi, L., Williams, H. S., Sheville, E., 음 and Sherlock, S. (1961). The demonstration of porta-pulmonary anastomoses in portal cirrhosis with the use of radioactive krypton $\left(\mathrm{Kr}^{85}\right)$. New Engl. J. Med., 265, 410. Short, D. S. (1958). Arteries of intestinal wall in systemic hypertension.
Lancet, 2, 1261.

Smith, R. Abbey (1956). A theory of the origin of intralobar seques-

tration of lung. Thorax, 11, 10. (1950). Arteriovenous shunts in
Tobin, C. E., and Zariquiey, M. O. (1950) the human lung. Proc. Soc. exp. Biol. (N.Y.), 75, 827.

Turner-Warwick, M. (1961). The bronchial artery patterns in pul-W monary and cardiovascular disease. Ph.D. Thesis, London $\sigma$ University.

Weibel, E. (1959). Die Blutgefässanastomosen in der menschlichen Lunge. Z. Zellforsch., 50,653 . 